\title{
A Constitucionalização do Direito da Cidade
}

\author{
City law constitucionalisation
}

Emerson Affonso da Costa Moura

\section{Resumo}

As transformações ocorridas no Direito da Cidade pela inclusão do seu regime fundamental na Constituição Federal e pela releitura de suas normas, institutos e categorias ao filtro axiológico da lei fundamental é o tema posto em debate. Analisa-se em que medida o processo de constitucionalização do Direito da Cidade promove uma releitura nas relações públicas e privadas no espaço urbano. Para tanto, no primeiro capítulo, analisa-se a ascensão do constitucionalismo contemporâneo de forma a extrair o papel de centralidade assumido pela Constituição e os Direitos Fundamentais na ordem jurídica extraindo uma ordem de valores. Após, no segundo capítulo, estuda-se o fenômeno da Constitucionalização do Direito com seus requisitos, seus principais elementos e efeitos e a sua irradiação para o direito infraconstitucional. Por fim, no terceiro capítulo, verifica-se em que medida o fenômeno da constitucionalização-inclusão e constitucionalização-releitura produz uma alteração no Direito da Cidade, adequando suas normas formal e materialmente à luz dos preceitos fundamentais.

Palavras-chaves: Neoconstitucionalismo. Constitucionalização. Direito da cidade.

\section{Abstract}

The changes that occurred in the City Law inclusion of its fundamental rule in the Constitution and the reinterpretation of its rules, institutions and categories to axiological filter the fundamental law is the theme put into discussion. Analyzes to what extent the constitutional process of the City Law promotes a reinterpretation in public and private relations in urban space. Therefore, the first chapter analyzes the rise of contemporary constitutionalism in order to extract the role of centrality assumed by the Constitution and fundamental rights in the legal system by extracting an order of values. After, in the second chapter, we study the phenomenon of constitutionalisation of law

EACM é professor assistente da Universidade Federal de Juiz de Fora (UFJF), doutorando em Direito pela Universidade do Estado do Rio de Janeiro (UFRJ), e-mail: emersonacmoura@yahoo.com.br 
with its requirements, its main elements and effects and its irradiation to the right infra. Finally, in the third chapter, there is to what extent the phenomenon of constitutionalization-inclusion and constitutionalising-rereading produces a change in city law, adapting its formal rules and materially in the light of the fundamental precepts.

Keywords: Neoconstitutionalism. Constitutionalising. Right to the city.

\section{Introdução}

Observa-se com o término da segunda guerra mundial, na Europa, e o advento do processo de redemocratização do Brasil, uma série de transformações na forma de organização política e jurídica estatal, que marcam a ascensão dos pilares fundamentais que denotam a construção de um constitucionalismo contemporâneo.

Com a promulgação da Constituição Federal de 1988 observa-se a consolidação dos pilares de um modelo constitucional, marcado pelo reconhecimento normativo, a ascensão axiológica da lei fundamental e a posição de centralidade do homem juntamente a seus direitos na ordem jurídica.

Esse novo status, assumido pelos direitos do homem, demanda a irradiação de sua força normativa por todo o ordenamento jurídico, condicionando a interpretação das normas e institutos dos ramos do Direito e, vinculando a atuação dos poderes públicos, que passam a encontrar legitimidade na concretização de seus preceitos.

Em um vértice, abrange a constitucionalização-inclusão que resulta em uma ampla disciplina normativa pela lei fundamental, a qual passa a instituir o regime básico do direito infraconstitucional tanto seu aspecto orgânico - ao definir as competências e procedimentos - quanto no aspecto inorgânico - ao delimitar os direitos fundamentais e os fins esperados.

Em outro plano, a constitucionalização-releitura refere-se à conformação das normas, categorias e institutos urbanísticos infraconstitucionais ao vetor axiológico da Constituição Federal, de forma a orientar a criação, interpretação e aplicação, aos bens e valores essenciais da sociedade, consagrados na lei fundamental.

Embora seja comum a doutrina fixar os efeitos promovidos pela constitucionalização no Direito Administrativo, Civil e Penal, no Direito da Cidade no qual a Constituição Federal de 1988 realizou ampla transformação, ao fixar os alicerces de seu regime fundamental de forma ampla e reorientar a aplicação de suas normas legais a nova ordem de valores e direitos.

Isto implica em uma reordenação das relações públicas e privadas realizadas no âmbito do espaço urbano, aos novos vetores trazidos pela Constituição Federal, adequando o uso pelos cidadãos e a regulação pelo Estado da propriedade pública e privada às funções sociais da Cidade.

Busca o presente trabalho, portanto, fixar as transformações ocorridas no Direito da Cidade pela inclusão do seu regime fundamental na Constituição Federal e pela releitura de suas normas, institutos e categorias ao filtro axiológico da lei fundamental, com suas repercussões nas relações públicas e privadas no espaço urbano.

Para tanto, primeiramente, é preciso analisar a ascensão do constitucionalismo contemporâneo de forma a extrair, a partir desse marco teórico eleito, o papel de centralidade assumido pela Constituição e os Direitos Fundamentais na ordem jurídica extraindo uma ordem de valores.

Na sequência, é estudado o fenômeno da Constitucionalização do Direito com seus requisitos, seus principais elementos e efeitos e, a sua irradiação para o direito infraconstitucional, de maneira a definir a reorientação das normas, categorias e institutos dos ramos do Direito à luz da Constituição.

Por fim, verifica-se em que medida o fenômeno da constitucionalização-inclusão e constitucionalização-releitura produz uma alteração no Direito da Cidade, adequando suas normas formal e materialmente à luz dos preceitos fundamentais, extraindo seus principais efeitos nas relações públicas e privadas.

Nesse tocante, utiliza-se por metodologia neste trabalho a crítica dialética como meio de pesquisa, em especial bibliográfica, fundado na doutrina jurídica nacional e estrangeira quando pertinente, bem como, a legislação pátria aplicável, no que coube, para a fundamentação desse trabalho. 


\section{O neoconstitucionalismo}

Observa-se, com o término da segunda guerra mundial na Europa e o advento do processo de redemocratização do Brasil, uma série de transformações na forma de organização política e jurídica estatal, que marcam o advento do Estado Constitucional de Direito e a ascensão dos pilares fundamentais do constitucionalismo contemporâneo ${ }^{1}$.

Como marco normativo, tem-se a promulgação da Lei Fundamental de Bonn na Alemanha e a Constituição da Itália, e a posteriori, das cartas fundamentais de Portugal e Espanha. No Brasil com o Constituição Federal de 1988 têm-se o ambiente propício para a garantia da estabilidade institucional e da aplicabilidade das normas constitucionais ${ }^{2}$.

Sob a designação de neoconstitucionalismo compreendem-se distintas vertentes ${ }^{3}$ que consolidam os novos paradigmas do fenômeno político-jurídico produzindo mudanças na compreensão do Direito, garantindo a crescente reaproximação entre Direito e os valores de ética e justiça, em contraponto ao distanciamento do modelo anterior ${ }^{4}$.

Na vertente da dogmática, envolve o processo de incorporação de elenco de direitos fundamentais aos textos constitucionais, com o reconhecimento além de sua dimensão subjetiva de proteção de situações individuais em face do poder público e dos particulares,

\footnotetext{
1 Sobre o tema: Carbonell, M. (2003). Nuevos Tiempos para el Constitucionalismo in: M. Carbonell (Org). Neoconstitucionalismo(s). (1 ed, p.9). Madrid: Editorial Trotta.

2 Tratando do tema no Brasil: Barroso, L. R. (2007). Neoconstitucionalismo e a Constitucionalização do Direito. 0 Triunfo Tardio no Direito Constitucional no Brasil in: D. Sarmento \& C. P. de Souza Neto (Orgs). A Constitucionalização do Direito: Fundamentos Teóricos e Aplicações Específicas. Rio de Janeiro: Lumen Juris, p. 205.

3 Abrange, portanto, as teorias de Luigi Ferrajoli, Gustavo Zagrebelsky, Luis Prieto Sanchís, Carlos Nino, Robert Alexy, Ronald Dworkin dentre outros. Sobre as distintas perspectivas teóricas e suas características comuns, vide por todos: Pozzolo, S. (1998). Neoconstitcuionalismo Y Especifidad de La Interpretacion Constitucional. Doxa, 21(II), 340.

4 Adota-se como ponto de partida para este breve estudo do fenômeno, os planos de análises propostos por Miguel Carbonell, mediante abordagem das transformações ocorridas nas Constituições, nas práticas judiciais e no desenvolvimento teórico dos modelos constitucionais. Carbonell, M. (2009). Neoconstitucionalismo: Elementos para una definición. In: E. R. Moreira \& M. Pugliesi. 20 Anos da Constituição Brasileira. São Paulo: Editora Saraiva, p. 197-208.
}

do seu ângulo objetivo como a consagração da ordem objetiva dos valores essenciais à sociedade.

Liga-se a dimensão objetiva a compreensão de que os direitos fundamentais consagram os valores mais importantes da comunidade política potencializando a sua irradiação para todos os campos do Direito, e sua eficácia enquanto fins ou valores comunitários sobre uma miríade de relações jurídicas. ${ }^{5}$

Com a expansão da jurisdição constitucional, mediante a ampliação do elenco de legitimados para a propositura das ações de controle e a criação de novos instrumentos de controle concentrado, garante-se a preservação dos direitos fundamentais do processo político majoritário reservando sua tutela a seara do Poder Judiciário ${ }^{6}$.

No campo da prática judicial, abrange a reelaboração da interpretação constitucional com o redimensionamento da norma jurídica como veiculadora apenas dos elementos iniciais para a solução do problema, a assunção dos fatos enquanto instrumento de delimitação dos resultados possíveis e o intérprete sendo um dos sujeitos que participa na criação do Direito ${ }^{7}$.

Enseja a definição de métodos interpretativos mais flexíveis e compatíveis com as hipóteses onde há a incidência multidimensional de normas jurídicas e complexidade dos fatos em questão, permitindo mediante concessões recíprocas a preservação dos bens

50 tema foi desenvolvido amplamente por: Sarmento, D. Direitos Fundamentais e Relações Privadas. Rio de Janeiro: Lumen Juris, 2004. p. 371.

6 Insere-se, portanto, o exercício da jurisdição constitucional orgânica e das liberdades no complexo de mecanismos de natureza normativa, institucional ou processual tendentes a assegurar a plena realização dos direitos fundamentais. Coelho, R. J. P. (2005). Mecanismos de Proteção dos Direitos Fundamentais. Brasília: Ordem dos Advogados do Brasil, p. 34.

7 Altera-se o papel do Poder Judiciário que passa a ter a competência ampla para invalidar atos legislativos e administrativos considerados como inconstitucionais e interpretar as normas jurídicas à luz da Constituição, com o preenchimento das antinomias e lacunas. Ferrajoli, L. Pasado Y Futuro Del Estado De Derecho. In: M. Carbonell. (Org). Neoconstitucionalimo(s)... Ob. cit. p. 18. 
e interesses em jogo, sempre reconduzindo ao sistema jurídico e a concordância prática ${ }^{8}$.

Na vertente da teoria jurídica, importa no reconhecimento da força normativa da Constituição, com o rompimento da concepção da lei fundamental como um mero documento político que veicula convite à atuação dos poderes públicos, mas a atribuição do status de norma jurídica delimitando limites e impondo deveres de atuação para o Estado?.

Na nossa experiência constitucional antes restrita a Constituições "garantistas" que tutelavam as liberdades formais como repositórios de promessas vagas significa a interrupção do ciclo inicial de baixa normatividade das disposições que veiculavam os direitos fundamentais, em especial, das normas que declaravam os direitos sociais, com o reconhecimento da aplicabilidade direta e imediata de seus preceitos $^{10}$.

Compreende, ainda, a posição de centralidade assumida pelos direitos fundamentais no sistema jurídico, instituindo uma ordem objetiva de valores e irradiando sua força normativa por todo o ordenamento, condicionando a interpretação das normas e institutos dos ramos do Direito e vinculando a atuação dos poderes públicos.

Os direitos fundamentais passam, portanto, sob a égide deste novo modelo constitucional a exercer uma dupla ordem de sentido: como vínculos

80 emprego da técnica legislativa de conceitos jurídicos indeterminados dotados de maior plasticidade e textura aberta e o reconhecimento de normatividade dos princípios com menor densidade jurídica inviabilizam que o intérprete extraia das normas em abstrato os elementos necessários a sua aplicação, sujeitando-se às suas valorações e escolha entre as soluções possíveis, mediante a ponderação entre os bens envolvidos e argumentação como elemento de controle da racionalidade da decisão proferida. Sobre o tema: Reis, J. (2006). Interpretação Constitucional e Direitos Fundamentais. Rio de Janeiro: Renovar. Em especial capítulo III.

9 Uma das obras percussoras sobre o tema é A Força Normativa da Constituição de Konrad Hesse extraída a partir de sua aula inaugural na cátedra da Universidade de Freiburg. Segundo o autor, a norma constitucional não tem existência autônoma em face da realidade, mas tão pouco se limita ao reflexo das condições fáticas: sua essência reside na pretensão de eficácia, de sua concretização na realidade imprimindo-lhe ordem e conformação. Hesse, K. A Força Normativa da Constituição. Porto Alegre: Sergio Antonio Fabris Editor, 1991. p 14-15.

${ }^{10}$ Sobre o tema vide: Barroso, L. R. O Direito Constitucional e a Efetividade de suas Normas: Limites e Possibilidades da Constituição Brasileira. 7 ed. Rio de Janeiro, Renovar, 2003. Em especial Capítulo IV. axiológicos, que condicionam a validade material das normas produzidas e enquanto fins que orientam o Estado Constitucional de Direito ${ }^{11}$.

Por efeito, com a expansão da jurisdição constitucional, o Poder Judiciário assume um novo papel na promoção dos direitos fundamentais, que aliado ao acréscimo da demanda social por justiça e a recuperação de suas garantias institucionais, resulta na sua ascensão político-institucional e na expressiva judicialização das questões políticas e sociais.

Corresponde a chamada onipotência judicial, decorrente da compreensão que sendo a Constituição uma norma jurídica presente em todo tipo de conflito, em razão do seu denso conteúdo material, a grande maioria das questões da vida social e política se submetem ao controle pelo Poder Judiciário, que acaba assumindo um papel proeminente nas questões. ${ }^{12}$

Note, porém, que a força irradiante da Constituição não se limitou apenas à reconstrução dinâmica de seus próprios enunciados de norma numa espécie previsível de auto-alimentação constitutiva, mas se projetou para todo o sistema jurídico, revisando o sistema de fontes e reestruturando seus pilares deontológicos ${ }^{13}$.

Através do reconhecimento da supremacia axiológica da Constituição e do novo status dos direitos fundamentais na ordem jurídica, deriva um processo de apreensão do sistema sob a ótica da Constituição com o objetivo de realizar os bens e valores fundamentais veiculados, em um processo designado de constitucionalização do Direito.

0 tema será tratado a seguir.

\section{A Constitucionalização do Direito}

Corresponde a Constitucionalização do Direito à transformação do ordenamento jurídico oriundo de sua impregnação pelas normas constitucionais, que passam a redimensionar as atividades legislativa, judicial e doutrinária ao novo papel de

\footnotetext{
${ }^{11}$ A expressão é utilizada pelo autor: Ferrajoli, L. Derechos e Garantias: La ley del mais débil. 1 ed. Madrid: Trotta, 1999. p. 22.

${ }^{12} \mathrm{O}$ conceito é do autor: Sanchís, L. P. Neoconstitucionalismo Y Ponderación Judicial. In Carbonell, Miguel. Neoconstitucionalismos. Ob. cit. p. 122.

13 Neste sentido: Sampaio, J. A. L. Mito e História da Constituição: Prenúncios Sobre a Constitucionalização do Direito. In: Souza Neto, C.P. e Sarmento, D. A Constitucionalização... Ob. cit. p. 200.
} 
centralidade assumido pela Constituição nas relações com os poderes públicos e com a sociedade.

No âmbito da legislação, abrange a limitação do espaço de conformação do Poder Legislativo, subtraindo de sua esfera de liberdade a definição dos bens e interesses a serem perseguidos, reservando a este precipuamente a eleição dos meios necessários a concretização dos fins e objetivos almejados pela sociedade e veiculados pela Constituição ${ }^{14}$.

No campo da jurisprudência, envolve a ampliação da competência do Poder Judiciário oriunda do poder-dever de aplicar os preceitos constitucionais, que importa na possibilidade de invalidação dos atos emanados pelos poderes públicos ou originários dos particulares através da interpretação criativa das normas jurídicas à luz da Constituição $0^{15}$.

No espaço da doutrina, inclui a releitura dos preceitos e institutos dos distintos ramos jurídicos com a recondução dos seus fundamentos axiológicos às normas constitucionais e o alinhamento do seu conteúdo normativo como revelação dos preceitos fundamentais veiculados pela Constituição garantindo a superioridade de suas normas e a realização dos valores da sociedade ${ }^{16}$.

\footnotetext{
${ }^{14}$ No Estado Constitucional de Direito a Constituição não apenas disciplina as formas de produção legislativa, porém, impõe também o conteúdo das leis, adequados aos bens e interesses fundamentais veiculados pelas normas constitucionais, garantindo limites aos poderes da maioria. Ferrajoli, L. Ob. cit. p. 18-19.

${ }^{15}$ Quando o Poder Judiciário desempenha uma função criadora do Direito em seu sentido forte, com a interpretação criativa da Constituição não importa sua desvinculação a lei como proposta pelo Direito Livre, mas no emprego de normas constitucionais capazes de imprimir maior determinação em frente ao conteúdo vago, inconcreto ou poroso da legislação. Sanchís, L. P. (2003). Sobre el Neoconstitucionalismo y Sus Implicaciones in: Justicia Constitucional y Derechos Fundamentales. Madrid: Trotta, p 129-131.

${ }^{16}$ Neste vértice, a Constituição corresponde a um centro de convergência, que condiciona os conteúdos de produção do direito, sujeitos a heterogeneidade e ocasionalidade das pressões sociais, aos princípios e valores constitucionais superiores sobre o qual existe um consenso social suficientemente amplo. Zagrebelsky, G. (2002). El Derecho Dúctil: ley, derechos y justicia. 4 ed. Madrid: Editorial Trotta, p. 14, 39-40.
}

Embora a constitucionalização do Direito decorra principalmente do reconhecimento da força vinculante dos preceitos constitucionais e do papel de centralidade dos direitos fundamentais na ordem jurídica para que se opere a completa impregnação da ordem jurídica pelas normas constitucionais, torna-se necessário o preenchimento de outras condições necessárias ${ }^{17}$.

De início, impõe-se a existência de uma constituição rígida aferida através da definição de um procedimento de modificação das normas constitucionais distinto do processo ordinário de formação das leis, que garanta a distinção de níveis hierárquicos normativos na ordem jurídica e a preeminência dos preceitos constitucionais sobre as demais normas jurídicas ${ }^{18}$.

Neste tocante, demonstra-se essencial a criação de um mecanismo de garantia da Constituição capaz de preservar a hierarquia de seus preceitos exteriorizado na previsão de um ou mais órgãos políticos ou judiciais incumbidos de exercer o controle de conformidade das leis e atos normativos emanados pelos poderes públicos às normas constitucionais ${ }^{19}$.

Envolve, ainda, a compreensão de que toda decisão legislativa é pré-disciplinada por normas constitucionais, idôneas, portanto, a regular de forma explícita ou implícita qualquer aspecto da vida política e social. Isto importa no reconhecimento

\footnotetext{
17 Adota-se o modelo proposto por Riccardo Guastini onde são consideradas determinadas condições para que um ordenamento jurídico possa ser considerado completamente impregnado pelas normas constitucionais. Guastini, R. La Constitucionalizacion Del Ordenamiento Juridico. In: M. Carbonell (Coord.) Neoconstitucionalismo(s)... Ob. cit. p. 50-56.

${ }^{18}$ Nesta ordem de idéias, a constitucionalização se apresentará mais acentuada nos ordenamentos jurídicos marcados pela super rigidez, ou seja, pela existência de um cerne imodificável do texto constitucionais, formado por preceitos não são sujeitos a procedimento de modificação, em decorrência de seu status político ou carga valorativa. Vieira, O. V. (1999). A Constituição e sua Reserva de Justiça: Um Ensaio Sobre Os Limites Materiais Ao Poder de Reforma. São Paulo: Malheiros.

19 Dentre os variados sistemas de controle de constitucionalidade, destaca-se o modelo francês de controle concentrado e preventivo exercido por órgão político e americano de controle abstrato e preventivo exercido por órgão judicial. O modelo brasileiro é eclético adotando todas as espécies e modalidades admitidas no Direito Comparado. Sobre o tema vide: Cappelletti, M. (1984). O Controle Judicial de Constitucionalidade das Leis no Direito Comparado. Porto Alegre: Sergio Antonio Fabris.
} 
da inexistência de qualquer questão que não esteja sujeita ao controle de parametricidade com a Constituição ${ }^{20}$.

A hermenêutica constitucional abrange o emprego da técnica de eleição dentre as distintas formas de interpretação aquela capaz de harmonizar o conteúdo da lei com a Constituição, de modo a preservar o princípio majoritário, evitando sua contrariedade com as normas constitucionais e garantindo a manutenção da validade da lei $^{21}$.

Por fim, inclui a influência da Constituição sobre as relações políticas, aferida através da atribuição aos órgãos de controle de constitucionalidade da resolução de conflitos de competência relativo ao exercício do poder estatal, do controle do exercício da discricionariedade legislativa pelo Poder Judiciário e do emprego das normas constitucionais na argumentação dos atores políticos ${ }^{22}$.

Na nossa ordem jurídica, o fenômeno de constitucionalização inicia-se com a promulgação da Constituição da República de 1988, em um processo que resultou no seu deslocamento para o eixo central do sistema jurídico e reconhecimento da sua

${ }^{20}$ Isto não significa desconsiderar que existem questões de natureza política sujeitas ao princípio majoritário, porém, compreender que existem outros princípios a serem preservados na ordem constitucional. Compete ao Poder Judiciário, portanto, resguardar o processo democrático e promover os valores fundamentais constitucionais, assim como assegurar a liberdade institucional. Barroso, L. R. Dez Anos da Constituição Brasileira de 1988. Revista de Direito Administrativo no 214.

${ }^{21}$ Corresponde a chamada interpretação conforme a constituição que implica na dúvida em relação à constitucionalidade de uma norma jurídica plurisignificativa deve o órgão eliminar as opções incompatíveis com o ordenamento jurídico, optando pela interpretação que se demonstre em consonância com a Constituição, mediante a redução do conteúdo normativo, desde que não afete a expressão literal da norma. Mendes, G. F. Controle de Constitucionalidade na Alemanha: A Declaração de Nulidade da Lei Inconstitucional, a Interpretação Conforme à Constituição e a Declaração de Constitucionalidade da Lei na Jurisprudência da Corte Constitucional Alemã. In: Revista de Direito Administrativo, no 193,1993 p. 22-27.

${ }^{22}$ Correspondem aos efeitos políticos produzidos pela constitucionalização sobre as relações entre os poderes estatais, dentre as quais se destaca o papel de protagonismo ocupado pelo Poder Judiciário, que é objeto de críticas uma vez que poderia gerar a judiocracia, ou seja, com a transferência das decisões políticas dos representantes eleitos para os juízes. Sobre o tema: Sarmento, D. O Neoconstitucionalismo no Brasil: Riscos e Possibilidades. In: D. Sarmento (Coord). Filosofia e Teoria Constitucional Contemporânea. Rio de Janeiro: Lumen Juris, 2009. p. 133-139. supremacia axiológica, potencializada pela erradicação daqueles fatores mencionados ${ }^{23}$.

Oriundos de uma experiência constitucional marcada por uma inflação legislativa e uma insinceridade normativa ${ }^{24}$, onde as Constituições garantistas tutelavam as liberdades formais como repositórios de promessas vagas, a veiculação de amplo elenco de direitos fundamentais e a sua inserção dentre as restrições ao poder de reforma, reforçou a rigidez da Constituição ${ }^{25}$.

A previsão exaustiva dos bens e interesses sociais na lei fundamental produziu a subtração de distintas questões da vida política e social do alcance do legislador, que passaram a encontrar fundamentos imediatos nas normas constitucionais sujeitando-se, portanto, ao controle de adequabilidade com a lei fundamental ${ }^{26}$.

Neste ponto, a expansão da jurisdição constitucional, mediante a criação de novos mecanismos de controle de constitucionalidade e ampliação do elenco de legitimados ativos para a propositura das ações abstratas, garantiu a proteção das

${ }^{23}$ Neste tocante, realiza idêntico movimento translativo ocorrido na Alemanha onde sob a égide da Lei Fundamental de 1949 e consagrando o desenvolvimento doutrinário, o Tribunal Constitucional Federal assenta que os direitos fundamentais instituem uma ordem objetiva de valores, condicionando a interpretação de todas as normas e vinculando os poderes públicos.

${ }^{24}$ Não foi incomum a existência formal de Constituições que invocaram o que não estava presente, afirmavam o que não era verdade e prometiam o que não seria cumprido. Como e.g. tem-se a Constituição de 1969 que garantia os direitos à integridade física e a vida, com as prisões ilegais, a tortura e o desaparecimento de pessoas na ditadura. Barroso, L. R. 0 direito constitucional... Ob cit. p. 61.

${ }^{25}$ Acentua-se o processo de constitucionalização nos ordenamentos onde além da previsão de um procedimento especial de alteração das normas constitucionais, existem princípios constitucionais não sujeitos à reforma pelo poder constituinte derivado. Isto ocorre em nossa ordem jurídica onde é previsto além de um processo legislativo específico (artigo 60 caput) princípios sensíveis que não podem ser objeto de deliberação de proposta de emenda (artigo $60 \S^{\circ} \stackrel{0}{ }$ todos da Constituição). Guastini, R. Ob. cit. p. 51.

${ }^{26}$ A hospedagem no texto constitucional de inúmeros princípios vagos, inclusive, alguns de duvidosa dignidade constitucional, dotados de forte carga axiológica e poder de irradiação, favoreceram o processo de constitucionalização do Direito. Sarmento, D. O Neoconstitucionalismo...Ob cit. p. 125. 
normas constitucionais e a preservação de sua hierarquia mediante atuação pelo Poder Judiciário ${ }^{27}$.

Por efeito, a ampliação da competência do Poder Judiciário para o controle de constitucionalidade dos atos emanados pelos poderes públicos e o crescente exercício das ações abstratas pelos atores políticos e sociais, permitiu um processo de judicialização da política, que amplia a influência da Constituição sobre as relações políticas ${ }^{28}$.

A necessidade de reelaboração doutrinária da hermenêutica constitucional de forma a resguardar o processo democrático e a estabilidade institucional na promoção dos valores fundamentais, conduzindo à interpretação da lei conforme a Constituição quando possível evitando a contrariedade com os seus preceitos e garantindo a manutenção da validade da lei ${ }^{29}$.

Embora o processo de constitucionalização permeie os distintos ramos do ordenamento jurídico, promovendo o realinhamento dos preceitos e categorias às normas constitucionais, o fenômeno tem alcançado especial relevo, segundo a doutrina, na órbita de três grandes domínios infraconstitucionais exercendo importante papel na reinterpretação de seus institutos à luz da ótica constitucional: o direito civil, penal e administrativo.

\footnotetext{
${ }^{27}$ Amplia-se o objeto e escopo da jurisdição constitucional através da ampliação do elenco de legitimados ativos para a propositura da ação direta de inconstitucionalidade (artigo 103 inciso I a IX), da criação do controle de inconstitucionalidade por omissão (artigo 103 §2º) com a ação direta e o mandado de injunção (artigo 102 "q"), da previsão da arguição de descumprimento de preceito fundamental (artigo $102 \S 1^{\circ}$ ) dentre outros.

${ }^{28}$ Como ilustrações têm-se as decisões do Supremo Tribunal Federal quanto aos limites de investigação das Comissões Parlamentares, a fidelidade partidária, a Reforma da Previdência e a Reforma do Judiciário. Quanto aos direitos fundamentais têm-se a interrupção da gestação de fetos inviáveis, as pesquisas com células-troncos embrionárias e as políticas públicas de distribuição de medicamentos.

${ }^{29}$ Compete ao Poder Judiciário preservar as condições essenciais de funcionamento do Estado Democrático mediante a tutela dos princípios fundamentais e procedimentos adequados à participação e deliberação, Sobre o tema: Souza Neto, C. P. (2002). Jurisdição, Democracia e Racionalidade Prática. Rio de Janeiro: Renovar.
}

Na órbita civil, observa-se um deslocamento do Código Civil da posição central antes ocupada no sistema jurídico, com a sua submissão a um redimensionamento axiológico a partir da Constituição, em especial, com a irradiação da dignidade da pessoa humana ${ }^{30}$ e aplicabilidade dos direitos fundamentais nas relações privadas ${ }^{31}$.

No campo penal, observa-se o readequamento das normas e institutos penais aos preceitos constitucionais, mediante a sujeição da produção, valida$d e^{32}$ e interpretação ${ }^{33}$ das normas que disciplinam os crimes e o processo ao amplo catálogo de direitos fundamentais e ainda, a subtração da esfera de conformação do legislador da criminalização e descriminalização de algumas condutas.

Sob o prisma administrativo, a assunção pela Constituição do epicentro da ordem jurídica representa a força motriz de consolidação das mudanças que tem sofrido o direito administrativo com redimensionamento dos seus institutos aos direitos

30 Em um vértice, destaca-se a irradiação do princípio da dignidade da pessoa humana sobre as relações privadas, promovendo uma despatrimonialização e repersonalização do direito civil, com o reconhecimento da centralidade do homem e o desenvolvimento dos seus direitos de personalidade e, por efeito, a preeminência de sua tutela nas relações patrimoniais. Moraes, M. C. B. de. (2000). Constituição e Direito Civil: Tendências. In: Revista dos Tribunais, 779, p. 55, 59.

${ }^{31}$ Sob outro ângulo, engloba a aplicabilidade dos direitos fundamentais às relações privadas, que na vertente dominante, importa no reconhecimento de que as referidas normas constitucionais se aplicam com eficácia direta e imediata, mediante a ponderação entre o princípio da livre iniciativa e autonomia de vontade e o direito fundamental em jogo. Sobre o tema: Sarmento, D. Direitos Fundamentais e Relações Privadas. Rio de Janeiro: Lumen Juris, 2004.

32 No que toca a produção e validade, embora prevista a reserva de lei na matéria penal com liberdade do legislador na definição dos crimes e sanções, a Constituição atua como fonte de limitação material desta conformação, impondo a necessidade de existência de lesividade social na conduta e de adequação do bem jurídico tutelado aos demais valores veiculados pela lei fundamental. Prado, L. R. Bem Jurídico-Penal e Constituição. São Paulo: Revista dos Tribunais, 2003. p. 50

33 Quanto à interpretação, revela-se na tensão entre a pretensão punitiva do Estado e direitos individuais do acusado, a necessária observância das garantias fundamentais veiculadas pela Constituição e da proporcionalidade na ponderação dos bens e valores conflitantes, de modo a evitar uma aplicação arbitrária ou desmedida da pena e do seu regime de execução. Ferrajoli, L. Ob. cit. p. 26. 
fundamentais e o princípio democrático, em uma reaproximação com o direito constitucional ${ }^{34}$.

Todavia, papel primordial exerceu o processo de constitucionalização do Direito no âmbito do Direito a Cidade, trazendo ampla disciplina da matéria para a Constituição Federal de forma a fixar seu regime fundamental, bem como, irradiando seus preceitos na interpretação das normas infraconstitucionais.

O tema será tratado a seguir.

\section{A Constitucionalização do Direito da cidade}

O fenômeno de irradiação dos preceitos constitucionais pode ser analisado sobre dois prismas ${ }^{35}$ : a constitucionalização-inclusão quando institutos do direito infraconstitucional passam a elevar-se ao texto constitucional e constitucionalização-releitura quando há filtragem à luz da Constituição, em especial das noções de direitos fundamentais e democracia ${ }^{36}$.

No que tange, à constitucionalização-inclusão embora haja crítica da doutrina acerca da chamada inflação constitucional, o que conduz a um déficit de efetividade, ossificação e reformismo constitucional crônico ${ }^{37}$, inegável que o fenômeno permite adequar

\footnotetext{
${ }^{34}$ A compreensão de que a disciplina administrativa em uma ordem constitucional pluralista não pode se estruturar apenas com vértice no interesse público, mas igualmente encontra epicentro em outros valores e bens tutelados pela lei fundamental, como os direitos fundamentais e o princípio democrático, conduz ao reconhecimento de uma pluralidade de fundamentos do regime administrativo no Estado Democrático de Direito. Sob o tema, vide: Moura, E. A. da C. Um Fundamento Do Regime Administrativo: 0 Princípio da Prossecução do Interesse Público. Rio de Janeiro: Lumen Juris, 2014.

${ }^{35}$ A distinção foi empregada por: Mendonça, J. V.S. de. Souza Neto, C. P. de; Fundamentalização e fundamentalismo na interpretação do princípio constitucional da livre iniciativa. In: Souza Neto, C. P. de e Sarmento, D. (Orgs.). A Constitucionalização do direito. Rio de Janeiro: Lumen Juris, 2007, p. 709 ss.

${ }^{36}$ Todavia, o fenômeno da Constitucionalização não se limita apenas à irradiação no sistema político, mas importa na abertura da Constituição ao sistema econômico, financeiro e internacional. Torres, R. L. (2009). Tratado de direito constitucional financeiro e tributário, 1. Rio de Janeiro: Renovar.

${ }^{37}$ A expressão é do autor: Binenbojm, G. A Constitucionalização do Direito Administrativo no Brasil: Um Inventário de Avanços e Retrocessos. Revista Eletrônica sob a Reforma do Estado, Salvador, Instituto Brasileiro de Direito Público, n. 13, março/ abril/maio 2008. p. 32-34.
}

os regimes infraconstitucionais regulados antes de 1988 se adéquem a nova ordem constitucional ${ }^{38}$.

O Direito da Cidade, cujas disciplinas nas Constituições anteriores fora tímido ${ }^{39}$ e a falta de um estatuto, código, consolidação ou legislação infraconstitucional que conformasse seu conteúdo delineando uma política urbana ou a organização dos espaços utilizáveis não dotava de eficácia as normas constitucionais vigentes ${ }^{40}$.

Neste viés, a Constituição Federal de 1988 instituiu ao lado dos subsistemas como da Constituição Financeira e da Constituição Tributária, o regime jurídico fundamental do Direito da Cidade ao fixar competência dos entes federativos, normas procedimentais, políticas urbanas, princípios e diretrizes, bem como, direitos fundamentais correlatos.

Tendo por análise a parte orgânica, consagra a Carta de Outubro, no que se refere ao Sistema Constitucional de Partilha de Bens e Competências entre os entes federativos, a competência concorrente da União, Estados e Distrito Federal para legislar de forma concorrente sobre normas de Direito Urbanístico ${ }^{41}$.

${ }^{38}$ Também neste sentido: Justen Filho, M. Curso de Direito Administrativo. 8 ed rev. Ampla e atual. Belo Horizonte: Fórum, 2012. p. 83.

${ }^{39}$ Embora o Direito da Cidade encontre regulação normativa desde o Direito Luso-Brasileiro com as ordenações do reino, que fixavam princípios básicos e genéricos sobre a ordenação das povoações, bem como, no período imperial e depois republicano tenha havido crescente legislação acerca de regras de ordenação da cidade, planos e programas urbanísticos e de assentamentos fundiários, faltava um regime fundamental de Direito da Cidade, tendo as Constituições tímida disciplina das relações urbanas. Reis Filho, N. G. (2000). Contribuição ao Estudo da Evolução Urbana do Brasil (1500-1720). São Paulo: Pini, p. 77.

${ }^{40}$ Neste sentido: Moreira, M. A História do Estatuto da Cidade. In: Dallari, A. A.; Ferraz, S. (Coord). Estatuto da Cidade: Comentários à Lei Federal 10.257/2001. 1 ed. São Paulo: Malheiros, 2002. p. 31-36.

${ }^{41}$ Dispõe desta forma: Brasil, Constituição da República Federativa do Brasil, de 05 de Outubro de 1998. Art. 24 inciso I. 
Esta determina, também, competência legislativa e administrativa para a proteção do meio ambiente ${ }^{42}$, bem como proteção do patrimônio natural ${ }^{43}, \mathrm{o}$ que inclui o natural e artificial, rural e urbano, já que o meio ambiente resulta da interação dos seus elementos naturais e construídos formando um único sistema ${ }^{44}$.

Além de veicular a competência comum dos entes federados para promover políticas públicas de Direito da Cidade, como o planejamento e execução de programas que permitam a construção de moradias ou a melhoria das condições habitacionais, bem como, as condições de saneamento básico ${ }^{45}$.

Embora, como visto, seja voltada a Constituição Federal de 1988 ao federalismo cooperativo no que tange também a matéria de Direito da Cidade, fixa também atribuições de próprias de cada ente federado orientado pelo Princípio da Preponderância de Interesses, como competências próprias da União, Estados e Municípios.

Assim, determina caber à União a competência para estabelecer diretrizes para o Desenvolvimento Urbano, o que abrange de forma inclusiva, mas não exclusiva, orientações no que tange à habitação ao saneamento básico e transportes urbanos ${ }^{46}$, garantindo pela simetria a tentativa de redução das desigualdades sociais e locais.

A competência para estabelecer e executar planos urbanísticos nacionais e regionais de ordenação do território, junto a sua atribuição para planos de desenvolvimento econômico e social, traduz uma vinculação adequada ao nível federal, que traduz

${ }^{42}$ Dispõe desta forma: Brasil, Constituição da República Federativa do Brasil, de 05 de Outubro de 1998. Art. 24 inciso VI e 23 VI.

${ }^{43}$ Dispõe desta forma: Brasil, Constituição da República Federativa do Brasil, de 05 de Outubro de 1998. Art. 23 IIII.

${ }_{44}$ A formação e o desenvolvimento do meio ambiente natural no seio urbano ocorre em um ambiente precipuamente artificial, que demanda a integração dos aspectos naturais e culturais além de um obrigatório estudo transdisciplinar entre o direito à cidade e ambiental. Humbert, G. L. H. (2009). Direito Urbanístico e Função Socioambiental da Propriedade Imóvel Urbana. Belo Horizonte: Fórum, p. 43.

${ }^{45}$ Dispõe desta forma: Brasil, Constituição da República Federativa do Brasil, de 05 de Outubro de 1998. Art. 23 IX.

${ }^{46}$ Dispõe desta forma: Brasil, Constituição da República Federativa do Brasil, de 05 de Outubro de 1998. Art. 21 XX. potencialidades no plano interurbano para um desenvolvimento a nível nacional ${ }^{47}$.

Para os Estados, permite a possibilidade de criação de regiões metropolitanas, de aglomerações urbanas e microrregiões em municípios limítrofes, de forma a integrar a organização, o planejamento e a execução de funções públicas de interesse comum ${ }^{48}$, o que denota especial relevância nos serviços públicos prestados na cidade.

Todavia, na Constituição de 1988 ascende o Município, elevado ao status de ente federado, enquanto manifestação local do Estado Federado de representação mais próxima do cidadão e, portanto, dos problemas locais e do cotidiano, com um papel central no que tange ao Direito da Cidade.

Embora com rol de atribuições limitadas na partilha de competência entre os entes federados, coube ao Município a competência para dispor sobre ordenamento territorial mediante o planejamento e controle do uso, do parcelamento e da ocupação do solo urbano ${ }^{49}$, inclusive, com a instituição e cobrança do imposto predial territorial urbano ${ }^{50}$.

Ademais, determina a competência legislativa ${ }^{51}$ e administrativa do Município ${ }^{52}$ para a promoção da política pública urbana, com a edição do Plano Diretor e facultativamente lei específica que preveja sanções pelo descumprimento da função social da propriedade ${ }^{53}$, com a adoção das respectivas medidas de polícia ${ }^{54}$.

\footnotetext{
47 Neste sentido: Silva, J. A. da. p. 56.

${ }^{48}$ Dispõe desta forma: Brasil, Constituição da República Federativa do Brasil, de 05 de Outubro de 1998. Art. 25 §3º.

${ }^{49}$ Dispõe desta forma: Brasil, Constituição da República Federativa do Brasil, de 05 de Outubro de 1998. Art. 30 VIII.

${ }^{50}$ Dispõe desta forma: Brasil, Constituição da República Federativa do Brasil, de 05 de Outubro de 1998. Art. 156 inciso I.

${ }^{51}$ Dispõe desta forma: Brasil, Constituição da República Federativa do Brasil, de 05 de Outubro de 1998. Art. 182 §1으.

${ }^{52}$ Dispõe desta forma: Brasil, Constituição da República Federativa do Brasil, de 05 de Outubro de 1998. Art. 182 ab initio.

53 Dispõe desta forma: Brasil, Constituição da República Federativa do Brasil, de 05 de Outubro de 1998. Art. $182 \S 4^{\circ}$.

${ }^{54}$ As sanções pelo desatendimento da função social da propriedade, no viés da cidade, através da não edificação, subutilização ou não utilização do imóvel urbano, abrangem o parcelamento ou edificação compulsórios, após a incidência de IPTU progressivo e, por fim, a desapropriação urbanística sancionatória. Sobre o tema, vide: Lausé, V. R. (1992). Desapropriação Urbanística, Revista de Informação Legislativa, 29(114).
} 
Sob tal viés, impõe regras procedimentais no que tange ao processo legislativo relativo ao Direito da Cidade, com fins a garantia de realização do Princípio Democrático e do Pacto Federativo, no que tange a Preponderância de Interesses, no âmbito da produção de normas de ordenação do espaço urbano.

Assim, determina que os projetos de lei de interesse específico do Município, de sua cidade ou de seus bairros, serão dotados de iniciativa popular, cabendo a manifestação de pelo menos cinco por cento do eleitorado ${ }^{55}$, consagrando os pilares do Princípio da Gestão Democrática na Cidade, depois expressamente previsto no Estatuto da Cidade ${ }^{56}$.

Impõe, também, que o instrumento básico de política de desenvolvimento e de expansão urbana, o Plano Diretor, é de competência do Município, já que se refere a interesse local, devendo ser aprovado através de lei da Câmara Municipal, sendo obrigatório para cidades com mais de vinte mil habitantes ${ }^{57}$, sendo ampliada, após pela legislação ${ }^{58}$.

Fixa a Constituição Federal de 1988, não somente competências para instituir planos urbanísticos, mas cria por si só uma Política Pública Urbana Constitucional, com fins de ordenar o pleno desenvolvimento das funções sociais da cidade, bem como, garantir o bem- estar de seus habitantes ${ }^{59}$.

Em um capítulo próprio da Constituição Federal, institui-se as regras e princípios da política urbana, de caráter não programático, mas impositivo para

${ }^{55}$ Dispõe desta forma: Brasil, Constituição da República Federativa do Brasil, de 05 de Outubro de 1998. Art. 29 X.

${ }^{56}$ Sobre o tema vide: Lira, R. P. Direito urbanístico, estatuto da cidade e regularização fundiária. Revista de Direito da Câmara Municipal do Rio de Janeiro, Rio de Janeiro, v. 10, n. 15, jan/dez 2008, p. 27.

${ }^{57}$ Dispõe desta forma: Brasil, Constituição da República Federativa do Brasil, de 05 de Outubro de 1998. Art. 182 §1ํ․

${ }^{58}$ Determinou a Lei Federal no 10.257 de 2001 no artigo 41 a obrigatoriedade do plano diretor, também, para municípios integrantes de regiões metropolitanas e aglomerações urbanas, que pretendam utilizar as sanções pelo desatendimento da função social da propriedade já mencionados, integrantes de áreas de especial interesse turístico ou inseridas na área de influência de empreendimentos ou atividades com significativo impacto ambiental de âmbito regional ou nacional. Com a Lei Federal no 12.608 de 10 de Abril de 2012 em seu artigo 26 determinou-se, também, sua necessidade caso o Município esteja incluído no cadastro nacional de Municípios com áreas suscetíveis à ocorrência de deslizamentos de grande impacto, inundações bruscas ou processos geológicos ou hidrológicos correlatos.

59 BRASIL, Constituição da República Federativa do Brasil, de 05 de Outubro de 1998. Art. 182. os poderes públicos, impondo a competência, o procedimento e fins da ação estatal no âmbito do programa de ação na Cidade, cabendo garantir a eficiência e continuidade na sua implementação ${ }^{60}$.

Neste giro, enuncia, portanto, os princípios e diretrizes fundamentais básicos do Direito da Cidade, que atuam como vetores axiológicos para atuação legislativa e administrativa dos entes federativos, mas também, conforma o exercício das liberdades privadas do cidadão.

Consagra a diretriz de pleno desenvolvimento das Funções Sociais da Cidade, como as funções que atingem coletividade indeterminada - uma vez que não é possível identificar quais proprietários, moradores e transeuntes serão afetados pelas atividades desenvolvidas - e permitem garantir condições dignas de vida no ambiente urbano ${ }^{61}$.

Por efeito, enfeixa funções tipicamente sociais de habitação, trabalho, lazer e mobilidade - de cidadania - como educação, saúde, segurança e proteção - e de gestão - como a prestação de serviços, planejamento, preservação do patrimônio cultural e natural, e sustentabilidade urbana - que permitem o desenvolvimento humano e social na cidade ${ }^{62}$.

Veicula, como decorrências do Princípio Democrático e Federativo, o Princípio da Gestão Democrática que determina a participação da população na política pública urbana, através da iniciativa popular das leis de interesse local ${ }^{63}$, o Princípio da Cooperação, ao determinar a partilha de tarefas em matéria urbanística entre entes federados. ${ }^{64}$

${ }^{60}$ Neste sentido: Carvalho Filho, J. dos S. Propriedade, Politica Urbana e Constituição. Revista da EMERJ, v. 6, n. 23, 2003. p. 175.

${ }^{61}$ Neste sentido: Saule Junior, N. Direito à Cidade: Trilhas Legais para o Direito das Cidades Sustentáveis. Porto Alegre: Sérgio Antônio Fabris, 2002.p. 61.

${ }^{62}$ Sobre o tema, vide: Bernardi, Jorge Luiz; Garcias, Carlos Mello. As Funções Sociais da Cidade. Revista Direitos Fundamentais e Democracia. Vol 4. 1998

${ }^{63}$ Dispõe desta forma: Brasil, Constituição da República Federativa do Brasil, de 05 de Outubro de 1998. Art. 29 X.

${ }^{64}$ Dispõe desta forma: Brasil, Constituição da República Federativa do Brasil, de 05 de Outubro de 1998. Art. 24 inciso I. Dispõe desta forma: Brasil, Constituição da República Federativa do Brasil, de 05 de Outubro de 1998. Art. 24 inciso VI e 23 VI, Art. 23 IIII.

Dispõe desta forma: Brasil, Constituição da República Federativa do Brasil, de 05 de Outubro de 1998. Art. 23 IIII. 
Como consagração de um Princípio da Cidade Sustentável, impõe o planejamento para ação estatal, ao determinar competências para políticas públicas nacionais e regionais e fixar a política urbana local, impor a necessidade de ordenação e o controle do uso do solo, de previsão do desenvolvimento e expansão urbana através do plano diretor.

Ademais, enuncia direitos e deveres públicos subjetivos do cidadão exercidos no âmbito da cidade, no catálogo de direitos e deveres fundamentais, seja de natureza individual, social ou difuso, ao qual destacamos para análise, o direito de propriedade e o direito à moradia, com os seus correlatos deveres aos entes privados e públicos.

No que tange ao direito de propriedade ${ }^{65}$, em sua acepção clássica e individual, é o domínio sobre a coisa, que concede ao seu titular o direito de usar dar destinado a coisa a serviço do seu titular - fluir - perceber seus frutos naturais e civis - dispor - colocar a coisa a disposição material ou jurídica - e reivindicar contra a quem indevidamente a possua. ${ }^{66}$

Com a Constituição Federal de 1988, há irradiação do Princípio da Dignidade da Pessoa Humana sobre as relações privadas, gerando uma despatrimonialização e repersonalização do direito civil, com o reconhecimento da centralidade do homem e o seus direitos e, por efeito, a preeminência de sua tutela nas relações patrimoniais ${ }^{67}$.

Ademais, há uma funcionalização socioambiental da propriedade, que supera a visão unidimensional, de direito subjetivo de dado titular, para ser tido na sua interação com a totalidade dos membros da sociedade, de forma a adequar o seu conteúdo aos fins esperados pela coletividade e proteção do meio ambiente saudável ${ }^{68}$.

\footnotetext{
${ }^{65}$ Dispõe desta forma: Brasil, Constituição da República Federativa do Brasil, de 05 de Outubro de 1998. Artigo 5o XXII.

${ }^{66}$ Sobre as posições jurídicas consulte: Pereira, Caio Mario da Silva Instituições de Direito Civil. Volume 4. Direitos Reais. 18 ed. Rio de Janeiro: Forense, 2004. p. 93-98.

${ }^{67}$ Compete ao princípio ético-jurídico atribuir unidade valorativa e sistemática ao Direito Civil, regulamentando a autonomia de vontade em prol da solidariedade social, possibilitando o livre desenvolvimento da personalidade de cada um dos membros da comunidade. Moraes, M. C. B. de. (2000). Constituição e Direito Civil: Tendências Revista dos Tribunais, 779, p. 55 e 59.

${ }^{68}$ Humbert, G. L. H. Direito Urbanístico e Função Socioambiental da Propriedade Imóvel Urbana. Belo Horizonte: Fórum, 2009. p. 121-122.
}

Por um lado, implica em deveres de abstenção e de concretização dos entes privados e dos poderes públicos na adequação da propriedade privada aos fins sociais, como a impenhorabilidade da pequena propriedade rural produtiva ${ }^{69}$, a requisição administrativa ${ }^{70}$ e a desapropriação por necessidade ou utilidade pública, ou por interesse social ${ }^{71}$ dentre outros.

No âmbito da cidade, significa a conformação da propriedade urbana a função social da cidade, ou seja, ao atendimento das exigências fundamentais de ordenação da cidade expressas no plano diretor $^{72}$, bem como, o dever constitucional de utilização do solo urbano, sob pena de imposição das sanções, dentre as quais, uso de desapropriação como sanção ${ }^{73}$.

No que se refere ao direito a moradia, enunciado apenas através de força da Emenda Constitucional no 26 de 2002, não abrange somente as relações patrimoniais advindas da propriedade, mas possui um cunho eminentemente pessoal, que envolve a proteção a uma condição digna de abrigo ${ }^{74}$.

Corresponde ao seu reconhecimento como locus das relações individuais do ser humano - o lugar de seu abrigo e proteção, intimidade e vivência - das suas relações sociais próximas - de convivência com a família e a vizinhança - e gerais - de domicílio civil, penal e eleitoral, como condição para o exercício de sua dignidade, liberdades e cidadania ${ }^{75}$.

${ }^{69}$ Dispõe desta forma: Brasil, Constituição da República Federativa do Brasil, de 05 de Outubro de 1998. Art. 5 XXVI.

${ }^{70}$ Dispõe desta forma: Brasil, Constituição da República Federativa do Brasil, de 05 de Outubro de 1998. Art. 5 XXV.

${ }^{71}$ Dispõe desta forma: Brasil, Constituição da República Federativa do Brasil, de 05 de Outubro de 1998. Art. 5 XXIV.

${ }^{72}$ Dispõe desta forma: Brasil, Constituição da República Federativa do Brasil, de 05 de Outubro de 1998. Art. 182 §2ㅇ․

${ }^{73}$ Dispõe desta forma: Brasil, Constituição da República Federativa do Brasil, de 05 de Outubro de 1998. Art. 182 §4ㅇ․

${ }^{74}$ Neste sentido: Souza, S. I. N. de. Direito à Moradia e de Habitação. São Paulo: Revista dos Tribunais, 2008. p. 139.

${ }^{75}$ Em igual consideração: Pagani, E. A. $O$ Direito de propriedade e o direito à moradia: um diálogo comparativo entre o direito de propriedade urbana imóvel e o direito à moradia. Porto Alegre: EDIPUCRS, 2009. p. 122. 
Envolve uma moradia adequada como forma de garantir a melhoria continua de sua condição de vida $^{76}$, com adoção pelos Estados de políticas públicas de habitação que permitam realizar progressivamente este direito humano, bem como, estabelecer sistemas eficazes de sua proteção ${ }^{77}$.

Note, portanto, que sob tal parâmetros que ocorrerá a constitucionalização-releitura do Direito da Cidade, de forma a fazer uma releitura das normas, categorias e institutos da matéria de natureza infraconstitucional dando-lhes conformidade material em sua criação, interpretação e aplicação, ao que determina a Constituição Federal.

Isto significa conforma a ordem social trazendo uma pauta diretiva na atuação política dos Poderes Públicos e na ação privada da sociedade em geral ${ }^{78}$, de maneira a determinar seja na persecução do interesse público pelos entes estatais ou na autonomia de vontade dos sujeitos privados, a adequação ao enfeixo do regime jurídico-constitucional traçado.

No primeiro vértice, das relações públicas, isso acarreta no redimensionamento do papel dos poderes públicos na concretização de normas urbanística tendo em vista a diretriz de desenvolvimento das funções sociais da cidade e de realização dos direitos fundamentais individuais e sociais correlatos.

Por efeito, na aplicação de normas relativas ao parcelamento do solo urbano ${ }^{79}$ ou de registro público de imóveis ${ }^{80}$, deve ser dada a interpretação que garanta a concretização da função socioambiental da propriedade e realização do direito à moradia, superando os entraves, por exemplo, ao

\footnotetext{
${ }^{76}$ Foi tratado em: Organização das Nações Unidas, Assembleia Geral, Pacto Internacional dos Direitos Econômicos, Sociais e Culturais, 16 de dezembro de 1966. Art. 11. II.

77 Neste sentido: Saule Junior, N. Op. cit. p. 21.

${ }^{78}$ Sustentando de forma igual: Carrasco, A. de M. Jurisdicização e Promoção da Função Socioambiental da Propriedade Urbana. In: Mota, M.; Torres, M. A. Transformações do Direito de Propriedade Privada. Rio de Janeiro: Elsiever, 2009. p. 180.

${ }^{79}$ Dispõe desta forma: Brasil, Lei Federal no 6.766 de 19 de Dezembro de 1979

${ }^{80}$ Dispõe desta forma: Brasil, Lei Federal no 6.015 de 31 de
} Dezembro de 1973. reconhecimento da propriedade de assentamentos irregulares ${ }^{81}$.

No que tange, aos instrumentos de políticas públicas previstas no Estatuto da Cidade ${ }^{82}$, refere-se ao reconhecimento do dever-poder de implementação dos mecanismos pelos poderes públicos, para atendimento das funções sociais da cidade, com previsão no plano diretor e nas leis orçamentárias daqueles mecanismos administrativos, urbanísticos e financeiros legais ${ }^{83}$.

De igual maneira, na regulação normativa ou concretização administrativa das leis de Direito da Cidade - como a Concessão de Uso Especial de Imóvel Urbano ${ }^{84}$ - ou normas que se inserem na sua interface - como o regime de bens públicos do Código Civil ${ }^{85}$ - devem ser lidos a luz da realização daqueles princípios, diretrizes e direitos fundamentais.

No segundo vértice, das relações privadas, conduz a utilização da posse e do direito de propriedade, de forma a atender os preceitos constitucionais,

\footnotetext{
${ }^{81}$ Neste contexto, o regime de regularização fundiária instituído pela Lei Federal no 11.977 de 2009 busca ultrapassar ou ao menos minimizar tais entraves de distintas ordens requisitos demasiadamente específicos da disciplina jurídica geral de parcelamento do solo urbano que não se adéquam as referidas áreas, a especulação imobiliária na construção e venda de empreendimentos que impede o acesso a moradia pelas camadas populares, as influências e pressões nas áreas economicamente viáveis ou pelo oferecimento de equipamentos públicos, os limites financeiros do ente municipal para a construção de moradias popular, dentre outros - permitindo a regularização de uma situação fática consolidada de habitação e garantindo a concretização ao direito à moradia urbana.

${ }^{82}$ Dispõe desta forma: Brasil, Lei Federal no 10.257 de 10 de Julho de 2001. Art. 4.

${ }^{83}$ Sob tal viés, a crescente desocupação de imóveis urbanos em grandes capitais brasileiras, apesar do déficit de habitação, impõe a aplicação de instrumentos como parcelamento, edificação ou utilização compulsórios, usucapião especial de imóvel urbano e desapropriação urbanística sancionatória como um dever pelos poderes públicos

${ }^{84}$ Dispõe desta forma: Brasil, Medida Provisória no 2.220 de 04 de setembro de 2001

${ }^{85}$ Dispõe desta forma: Brasil, Lei Federal no 10.406 de 10 de Janeiro de 2002. Art. 98 a 103.
} 
que se aplicam com eficácia direta e imediata ${ }^{86}$, adequando-as, também, a diretriz de desenvolvimento das funções sociais da cidade e de realização dos direitos fundamentais individuais e sociais correlatos.

Isto significa que o exercício do direito de posse e propriedade, bem como, as relações decorrentes, tal qual o Direito de Vizinhança, devem atender as limitações urbanísticas, a função socioambiental, em especial, as funções da cidade e as demais diretrizes e princípios da disciplina, sob pena de configurar desvio ou abuso de direito, com as sanções legais.

\section{Conclusão}

Sob a égide de dado modelo teórico constitucional, a Constituição Federal de 1988 assume a posição de centralidade na ordem jurídica irradiando um conjunto de bens, valores e direitos, determinando a adequação formal e substancial de categorias, normas e institutos aos seus preceitos fundamentais.

O fenômeno abrange a ampla incorporação de matérias legais no texto constitucional e a interpretação das normas infraconstitucionais a luz do texto fundamental, garantindo com a constitucionalização-inclusão e a constitucionalização-releitura, a unidade do ordenamento jurídico com esteio na supremacia da Constituição.

Sob o primeiro aspecto, na Constituição Federal de 1988 ocorreu a disciplina de normas relativas a competência e procedimento, programas e princípios, direitos e deveres fundamentais, relativos a matéria urbanística, que consagram um amplo processo de constitucionalização do Direito da Cidade.

No que tange à segunda vertente, as leis infraconstitucionais devem ter sua criação, aplicação e interpretação orientadas por este regime jurídico-constitucional fundamental do Direito da Cidade, adequando seu conteúdo às funções sociais da cidade, o direito de moradia digna, a função

\footnotetext{
${ }^{86}$ Não se ignora, todavia, a existência da doutrina americana da state action que nega baseada na autonomia privada e no pacto federativo a eficácia dos direitos fundamentais nas relações privadas, bem como, no direito pátrio a teoria da eficácia indireta e imediata dos direitos fundamentais na esfera privada, que apenas reconhece a irradiação dos direitos fundamentais na interpretação das normas. Sobre o tema: Sarmento, D. (2004). Direitos Fundamentais e Relações Privadas. Rio de Janeiro: Lumen Juris.
}

socioambiental da propriedade, a gestão democracia, dentre outros.

Isto demanda, na atuação dos intérpretes constitucionais formais - no exercício de sua conformação legislativa ou discricionariedade administrativa - e dos sujeitos informais em uma sociedade aberta os cidadãos no exercício de sua autonomia privada - a sua orientação por estes vetores axiológicos fundantes da disciplina da cidade.

Por efeito, o processo de constitucionalização do Direito da Cidade não se encerra com a mera previsão dos deveres e condutas a serem observados nas relações públicas e privadas de caráter urbanístico, mas depende de sua efetiva concretização, trazendo efetividade as normas constitucionais e conformando a realidade urbana vigente.

Ao revés, corresponde a um processo em aperfeiçoamento ao qual demanda dos intérpretes a tentativa de extrair a máxima efetividade dos preceitos constitucionais na aplicação da legislação urbanística vigente, garantindo que a Constituição da Cidade possa ser plenamente concretizada.

Isso, todavia, não importa em considerar que com a inclusão e releitura pela constitucionalização do Direito da Cidade é possível resolver os problemas da realidade subjacente às normas legais, com a solução dos problemas da cidade, pois seria desconsiderar os próprios limites do Direito e os domínios das outras ciências.

Todavia, inevitável que como mecanismo de ordenação social, o ordenamento jurídico em um Estado Democrático de Direito, com epicentro em uma Constituição Federal, somente poderá buscar efetividade em sua atividade quando ao menos for capaz de conformar a própria aplicação de seus preceitos à lei fundamental e compromisso primeiro da sociedade. 


\section{Referências}

Alexy, R. (1997). Teoria de Los Derechos Fundamentales. Madrid: Centro de Estudios Constitucionales.

Aragão, A. S. de. (2006). Agências Reguladoras e Evolução do Direito Administrativo Econômico. Rio de Janeiro: Forense.

Ávila, H. (2005). Repensando o "Princípio da Supremacia do Interesse Público Sobre o Particular" In: D. Sarmento (Org). Interesses Públicos vs. Interesses Privados: Desconstruindo o Princípio de Supremacia do Interesse Público. Rio de Janeiro: Lumen Juris.

Baptista, P. (2003). Transformações do Direito Administrativo. Rio de Janeiro: Renovar, 2003.

Barcellos, A. P. de. (2006). Constitucionalização das Políticas Públicas em Matéria de Direitos Fundamentais: 0 Controle Político-Social e o Controle Jurídico no Espaço Democrático. Revista de Direito do Estado, 3.

Barroso, L. R. (1999). Dez Anos da Constituição Brasileira de 1988. Revista de Direito Administrativo no 214.

Barroso, L. R. (2003). O Direito Constitucional e a Efetividade de suas Normas: Limites e Possibilidades da Constituição Brasileira. 7ed. Rio de Janeiro: Renovar.

Barroso, L. R. (2006). Fundamentos Teóricos e Filosóficos do Novo Direito Constitucional Brasileiro: Pós-Modernidade, Teoria Crítica e Pós-Positivismo. In: R. Quaresma., \& M. L. de P. Oliveira. Direito Constitucional Brasileiro: Perspectivas e Controvérsias Contemporâneas. Rio de Janeiro: Forense.

Barroso, L. R. (2007). Neoconstitucionalismo e a Constitucionalização do Direito. O Triunfo Tardio no Direito Constitucional no Brasil. In: Sarmento, D. \& C. P de Souza Neto. (Orgs). A Constitucionalização do Direito: Fundamentos Teóricos e Aplicações Específicas. Rio de Janeiro: Lumen Juris, p. 205.

Bernardi, J. L., \& Garcias, C. M. (1998). As Funções Sociais da Cidade. Revista Direitos Fundamentais e Democracia, 4.

Binenbojm, G. (2008). A Constitucionalização do Direito Administrativo no Brasil: Um Inventário de Avanços e Retrocessos. Revista Eletrônica sob a Reforma do Estado, Salvador, Instituto Brasileiro de Direito Público, 13.

Bucci, M. P. D. (2002). Direito Administrativo e Políticas Públicas. São Paulo: Saraiva.
Canotilho, J. J. G. (2002). Direito Constitucional e Teoria da Constituição. Coimbra: Almedina.

Cappelletti, M. (1984). O Controle Judicial de Constitucionalidade das Leis no Direito Comparado. Porto Alegre: Sergio Antonio Fabris.

Carbonell, M. (2009). Neoconstitucionalismo: Elementos para una definición. In: E. D. Moreira, \& M. Pugliesi. 20 Anos da Constituição Brasileira. São Paulo: Editora Saraiva.

Carbonell, M. (2003). Nuevos Tiempos para el Constitucionalismo.In:M.Carbonell.(Org).Neoconstitucionalismo(s). Madrid: Editorial Trotta.

Carrasco, A. de M. (2009). Jurisdicização e Promoção da Função Socioambiental da Propriedade Urbana. In: M. Mota, \& M. A. Torres. Transformações do Direito de Propriedade Privada. Rio de Janeiro: Elsiever.

Carvalho Filho, J dos S. (2003). Propriedade, Política Urbana e Constituição. Revista da EMERJ, 6(23).

Castro, C. R. S. (2005). A Constituição Aberta e os Direitos Fundamentais: Ensaio Sobre o Constitucionalismo PósModerno e Comunitário. Rio de Janeiro: Forense.

Coelho, R. J. P. (2005). Mecanismos de Proteção dos Direitos Fundamentais. Brasília: Ordem dos Advogados do Brasil.

Dworkin, R. (2002). Levando os Direitos a Sério. São Paulo: Martins Fontes.

Falla, F. G. (1962). Las Transformaciones Del Regime Administrativo. Madri: Instituto de Estudios Politicos.

Falla, F. G. (1994). Tratado de Derecho Administrativo. Madrid: Tecnos, v 1-2.

Ferrajoli, L. (1999). Derechos e Garantias: La ley del mais débil. Madrid: Trotta.

Ferrajoli, L. (2003). Pasado Y Futuro Del Estado De Derecho. In: M. Carbonell (Org). Neoconstitucionalimo(s). Madrid: Editorial Trotta.

Ferreira, S.de A. (1991). Comentários à Constituição. Rio de Janeiro: Freitas Bastos.

Giorgianni, M. (1998). O Direito Privado e as suas Atuais Fronteiras. Revista dos Tribunais, 747.

Guastini, R. (2003). La Constitucionalizacion Del Ordenamiento Juridico. In: M. Carbonell (Coord.) Neoconstitucionalismo(s). Madrid: Editorial Trotta. 
Hesse, K. (1991). A Força Normativa da Constituição. Porto Alegre: Sergio Antonio Fabris Editor.

Humbert, G. L. H. (2009). Direito Urbanístico e Função Socioambiental da Propriedade Imóvel Urbana. Belo Horizonte: Fórum.

Justen Filho, M. (2012). Curso de Direito Administrativo (8 ed.) Belo Horizonte: Fórum.

Krell, A. J. (2004). Discricionariedade Administrativa e Proteção Ambiental: o controle dos conceitos jurídicos indeterminados e a competência dos órgãos ambientais: Um Estudo Comparativo. Porto Alegre: Livraria do Advogado.

Lausé, V. R. (1992). Desapropriação Urbanística. Revista de Informação Legislativa, 29 (114).

Lira, R. P. (2008). Direito urbanístico, estatuto da cidade e regularização fundiária. Revista de Direito da Câmara Municipal do Rio de Janeiro, 10(15).

Mendonça, J. V. S. de., \& Souza Neto, C. P. de. (2007). Fundamentalização e fundamentalismo na interpretação do princípio constitucional da livre iniciativa. In: C. P. de Souza Neto, \& D. Sarmento (Orgs.). A Constitucionalização do direito. Rio de Janeiro: Lumen Juris.

Mendes, G. F. (1993). Controle de Constitucionalidade na Alemanha: A Declaração de Nulidade da Lei Inconstitucional, a Interpretação Conforme à Constituição e a Declaração de Constitucionalidade da Lei na Jurisprudência da Corte Constitucional Alemã. Revista de Direito Administrativo, 193.

Moraes, M. C. B. de. (2000). Constituição e Direito Civil: Tendências. Revista dos Tribunais, 779.

Moreira, M. (2002). A História do Estatuto da Cidade. In: A. A. Dallari, \& S. Ferraz (Coord). Estatuto da Cidade: Comentários à Lei Federal 10.257/2001. São Paulo: Malheiros.

Moura, E. A. da C. (2014). Um Fundamento Do Regime Administrativo: 0 Princípio da Prossecução do Interesse Público. Rio de Janeiro: Lumen Juris.

Oliveira, R. C. R. (2009). A Constitucionalidade do Direito Administrativo: O Princípio da Juridicidade, a Releitura da Legalidade Administrativa e a Legitimidade das Agências Reguladoras. Rio de Janeiro: Lumen Juris.

Otero, P. (2003). Legalidade e Administração Pública: 0 sentido da vinculação administrativa à juridicidade. Coimbra: Almedina.
Pagani, E. A. (2009). O Direito de propriedade e o direito à moradia: um diálogo comparativo entre o direito de propriedade urbana imóvel e o direito à moradia. Porto Alegre: EDIPUCRS

Pereira, C. M. da S. (2004). Instituições de Direito Civil, 4. (18 ${ }^{\mathrm{a}}$ ed.) Rio de Janeiro: Forense.

Pozzolo, S. (1998). Neoconstitcuionalismo Y Especifidad de La Interpretacion Constitucional. Doxa, 21(II).

Prado, L. R. (2003). Bem Jurídico-Penal e Constituição. São Paulo: Revista dos Tribunais.

Reis, J. (2006). Interpretação Constitucional e Direitos Fundamentais. Rio de Janeiro: Renovar.

Reis Filho, N. G. (2000). Contribuição ao Estudo da Evolução Urbana do Brasil (1500-1720). São Paulo: Pini.

Sampaio, J. A. L. (2007). Mito e História da Constituição: Prenúncios Sobre a Constitucionalização do Direito. In: C. P. de Souza Neto, \& D. Sarmento (Orgs.). A Constitucionalização do Direito: Fundamentos Teóricos e Aplicações Específicas. Rio de Janeiro: Lumen Juris.

Sanchís, L. P. (2003). Neoconstitucionalismo Y Ponderación Judicial. In: M. Carbonell. Neoconstitucionalismo(s). Madrid: Editorial Trotta.

Sanchís, L. P. (2003). Sobre el Neoconstitucionalismo y Sus Implicaciones In: Justicia Constitucional y Derechos Fundamentales. Madrid: Trotta.

Sarmento, D. (2004). Direitos Fundamentais e Relações Privadas. Rio de Janeiro: Lumen Juris.

Sarmento, D. (2009). 0 Neoconstitucionalismo no Brasil: Riscos e Possibilidades. In: D. Sarmento. (Coord). Filosofia e Teoria Constitucional Contemporânea. Rio de Janeiro: Lumen Juris.

Saule Junior, N. (2002). Direito à Cidade: Trilhas Legais para o Direito das Cidades Sustentáveis. Porto Alegre: Sérgio Antônio Fabris.

Souza, S. I. N. de. (2008). Direito à Moradia e de Habitação. São Paulo: Revista dos Tribunais.

Souza Neto, C. P. (2002). Jurisdição, Democracia e Racionalidade Prática. Rio de Janeiro: Renovar.

Souza Neto, C. P. (2006). Teoria Constitucional e Democracia Deliberativa. Renovar: Rio de Janeiro. 
Tepedino, G. (2004). Premissas Metodológicas para a Constitucionalização do Direito Civil. In: G. Tepedino (Org). Temas de Direito Civil, 3. Rio de Janeiro: Renovar.

Vieira, O. V. (1999). A Constituição e sua Reserva de Justiça: Um Ensaio Sobre Os Limites Materiais Ao Poder de Reforma. São Paulo: Malheiros.

Zagrebelsky, G. (2002). El Derecho Dúctil: ley, derechos y justicia. 4 ed. Madrid: Editorial Trotta.

Submissão: 21/07/2016

Received: $21^{\text {th }}$ July2016

Aprovação: 28/10/2016

Approved: $28^{\text {th }}$ October 2016 